\title{
$\mathrm{HD}$ 음성 서비스를 제공하는 스마트폰 어플리케이션의 구현
}

최 승 한, ${ }^{1 \dagger}$ 김 도 영, ${ }^{2}$ 서 창 호 ${ }^{1}$

${ }^{1}$ 공주대학교, ${ }^{2}$ 한국전자통신연구원

\section{The Implementation of Smartphone Application servicing HD(High Definition)-Voice*}

\author{
Seung-Han Choi, ${ }^{{ }^{\dagger}}$ Do-Young Kim, ${ }^{2}$ Chang-Ho Seo ${ }^{1 \neq}$ \\ ${ }^{1}$ Kongju National University, ${ }^{2}$ ETRI
}

요 약

본 논문은 ITU-T 표준 코덱인 G.711.1 광대역 코덱을 적용한 HD 보이스 스마트폰 어플리케이션의 개발 내용을 설명한다. 개발 내용에는 G.711.1 광대역 코덱을 적용한 $\mathrm{HD}$ 보이스 스마트폰 어플리케이션의 구조와 개발된 $\mathrm{HD}$ 보이스 어플리케이션의 음성 품질 결과를 포함하고 있으며, ITU-T의 다른 표준 코덱인 G.722 코덱을 적용한 어플리 케이션 보다 음성 품질이 MOS값 - 0.5 (패킷 손실 환경 포함)로 향상된 결과가 나왔다.

\section{ABSTRACT}

This paper represents the development of the HD-Voice application with G.711.1 coder-the latest wideband codec standard from ITU-T-for smartphone based on android platform. The work also includes the structure of the HD-voice application and the result of speech quality of HD-Voice application with G.711.1 coder. The paper shows that the speech quality of HD-Voice application with G.711.1 coder is excellent.

Keywords: HD-Voice, G.711.1, G.722, Smartphone

\section{I. 서 론}

최근 사용자의 고품질 음성 서비스에 대한 요청과 고사양 스마트폰의 지원으로 MVNO(Mobile Virtual Network Operators), 기간 통신사 등의 서 비스 제공자, 카카오톡, 다음, 네이버 등의 콘텐츠 제 공자, 그리고, 스마트폰 어플리케이션 개발자들은

접수일(2013년 6월 4일), 수정일(1차: 2013년 7월 8일), 게재확정일 (2013년 7월 26일)

* 미래창조과학부 방송통신기술개발사업(ETRI연구개발지 원사업) [11-921-05-001] MEST(R01-2010-000-266 21-0) NRF 일환으로 수행하였습니다.

† 주저자, shchoi@etri.re.kr

\# 교신저자, chseo@kongju.ac.kr (Corresponding author)
$\mathrm{HD}$ 보이스 어플리케이션에 대한 개발의 필요성을 가 지게 되었다. 전통적인 음성 서비스는 제한된 전송 대 역폭으로 인해서 $300 \mathrm{~Hz} \sim 3.4 \mathrm{kHz}$ 협대역 음성 주파수를 사용했다[그림 1]. 하지만, 전송 대역폭의 증가와 $\mathrm{HD}$ 보이스에 대한 사용자들의 요청으로 50 $\mathrm{Hz} \sim 7 \mathrm{kHz}$ 광대역 음성 주파수를 적용한 $\mathrm{HD}$ 보 이스 기술을 개발하게 되었다. 현재, ITU-T(International Telecommunication Union-Telecommunication Standardization Sector) 의 광대역 주파수 기반의 광대역 코덱은 G.722, G.722.1 AMR-WB(H.722.2), G.729.1 G.718, 그리고 G.711.1 코덱이 표준으로 지정되어 있 다. [15] 


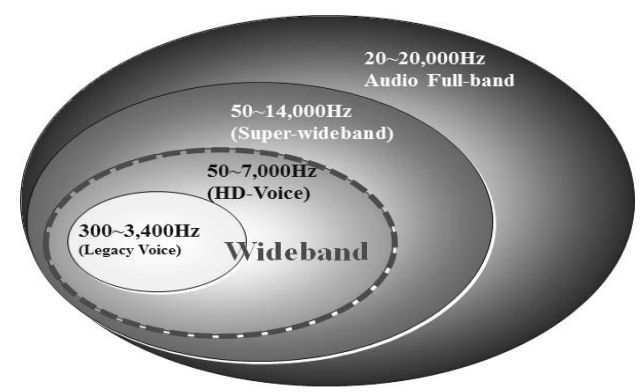

(그림 1) 오디오 주파수 대역의 분류

여러 개의 광대역 음성 코덱중에 G.711.1 코덱은 기존 대다수의 $\operatorname{VoIP}$ (Voice over IP) 단말에 적용 되는 G.711 협대역 코덱의 확장으로 G.711 코덱과 호환성을 가지기 때문에, 기존 VoIP 단말과 상호 연 동 할 수 있는 장점을 가진다. 즉, 기존 협대역 기반의 VoIP 망을 HD 보이스 망으로 변환하는 과정에서 비 용이 가장 적게 소요된다. 또한, G.711.1 광대역 코 덱의 손실 보정 기능은 패킷 손실이 빈번하게 발생하 는 네트워크 환경에서 음성 품질의 저하를 막는 기능 을 수행한다. 현재, WiFi, 3G, LTE Wibro 등과 같 은 무선 통신망에는 패킷 손실의 빈도가 유선망에 비 해서 많기 때문에, 손실 보정 기능의 중요성이 커지고 있다.

본 논문에서는 G.711.1 광대역 코덱, $\mathrm{HD}$ 보이스 미디어 엔진, $\mathrm{HD}$ 보이스 지원 시그널링 프로토콜을 포함하는 $\mathrm{HD}$ 보이스 스마트폰 어플리케이션의 구현 내용과 구현된 $\mathrm{HD}$ 보이스 스마트폰 어플리케이션의 음성 품질 결과를 설명하고자 한다.

\section{II. 배경 연구}

〔표 1]은 G.711/G.722/G.711.1 코덱의 특징을 비교한 표이다. G.711은 협대역 음성 신호를 인코딩 하는 코덱이며, G.722는 광대역 음성 신호를 인코딩 하는 코덱이다. G.711.1은 협대역 및 광대역 음성 신

〔표 1) G.711/G.722/G.711.1 코덱의 특징 비교

\begin{tabular}{|l|c|c|c|}
\hline \multicolumn{1}{|c|}{ Codec } & G.711 & G.722 & G.711.1 \\
\hline Bandwidth & Narrowband & Wideband & $\begin{array}{c}\text { Narrowband, } \\
\text { Wideband }\end{array}$ \\
\hline Type & PCM & Sub-band ADPCM & PCM+MDCT \\
\hline Bit-rate [kbit/s] & 64 & $\begin{array}{c}48,56,64 \\
\text { (embedded) }\end{array}$ & $\begin{array}{c}\text { 64(NB), } 80(\mathrm{NB}), \\
80(\mathrm{WB}), 96(\mathrm{WB})\end{array}$ \\
\hline Algorithmic delay[msec) & 0.125 & 1.625 & 11.875 \\
\hline Complexity[MIPS] & 0.34 & 10 & 8.70 \\
\hline
\end{tabular}

호 모두를 인코딩하는 코덱이다.

2008년 3월에, G.711 협대역 표준 코덱[1]의 확 장 코덱인 G.711.1 광대역 코덱[2]이 ITU-T 표준 코덱으로 승인되었다. 주요 특징으로는 코딩 알고리즘 은 저지연, 낮은 복잡도, 그리고, 기존 VoIP 단말과 의 트랜스코딩 문제를 해결하면서 고품질 음성을 유지 하도록 설계 되었다. 특히, G.711 코덱의 광대역 확 장 버전으로 IP 폰이나, 다자간 음성 컨퍼런스의 코덱 으로 적합하며, 기존 G.711 기반의 시스템이나 단말 과 끊김없는 서비스를 지원할 수 있는 특징을 가지고 있다[3][4][16]. IUT-T 소프트웨어 도구 라이브러 리(v2.2)의 의해서 측정된 복잡도는 가장 높을 때에 8.7 WMOPS(Weighted Million Operations Per Second)로 측정되었고, 지연은 $11.285 \mathrm{~ms}$ 로 측정되었다.

〔표 2〕 G.711.1 광대역 코덱의 모드에 따른 분류

\begin{tabular}{|c|c|c|c|c|c|}
\hline Mode & $\begin{array}{c}\text { Layer } \\
0\end{array}$ & $\begin{array}{c}\text { Layer } \\
1\end{array}$ & $\begin{array}{c}\text { Layer } \\
2\end{array}$ & Audio band & Blt rate \\
\hline R1 & $\mathbf{X}$ & - & - & Narrowband & 64 kbps \\
\hline R2a & $\mathrm{X}$ & $\mathrm{X}$ & - & Narrowband & $\mathbf{8 0 ~ k b p s}$ \\
\hline R2b & $\mathrm{X}$ & - & $\mathrm{X}$ & WIdeband & $\mathbf{8 0 ~ k b p s}$ \\
\hline R3 & $\mathrm{X}$ & $\mathrm{X}$ & $\mathrm{X}$ & WIdeband & $\mathbf{9 6}$ kbps \\
\hline
\end{tabular}

〔표 2)는 G.711.1 광대역 코덱의 모드와 서브비트 스트림(sub-bitstream)의 조합을 나타낸 표이다. 모드는 $64 \mathrm{~kb} / \mathrm{s}$ 비트스트림의 레이어0에 $16 \mathrm{~kb} / \mathrm{s}$ 비 트스트림의 레이어 1 과 레이어 2 를 조합해서, $\mathrm{R} 1$, $\mathrm{R} 2 \mathrm{a}, \mathrm{R} 2 \mathrm{~b}, \mathrm{R} 3$ 4가지 모드로 인코딩한다. R1, R2a 모드는 $8 \mathrm{kHz}$ 의 협대역 주파수이고, R2b, R3모드는 $16 \mathrm{kHz}$ 의 광대역 주파수이다.

$\mathrm{HD}$ 보이스 기반 어플리케이션을 개발하기 위해서 선택한 스마트폰 플랫폼은 안드로이드 플랫폼이다. 안 드로이드 플랫폼을 탑재한 스마트폰이 아이폰과 함께

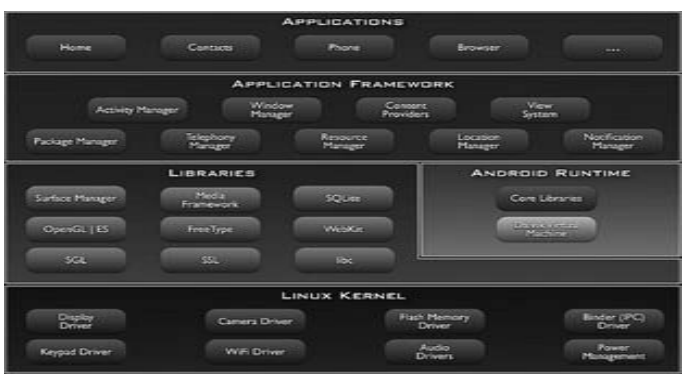

〔그림 2) 안드로이드 소프트웨어 구조 
가장 대중적으로 널리 사용되며, 플랫폼을 최적화하기 위한 개방 환경을 제공하기 때문에 선택했다. (그림 2]는 안드로이드 시스템의 소프트웨어 구조[13]를 도 시한 일반적인 그림이다. 안드로이드 플랫폼은 운영체 제인 리눅스 커널, 화면/사운드/멀티미디어 기능을 제 공하는 안드로이드 라이브러리, 자바 런타임 기능을 수행하기 안드로이드 런타임, 그리고, API 기반의 인 터페이스를 제공해서 다양한 으용을 개발 할 수 있도 록 하는 어플리케이션 프레임워크로 구성된다.

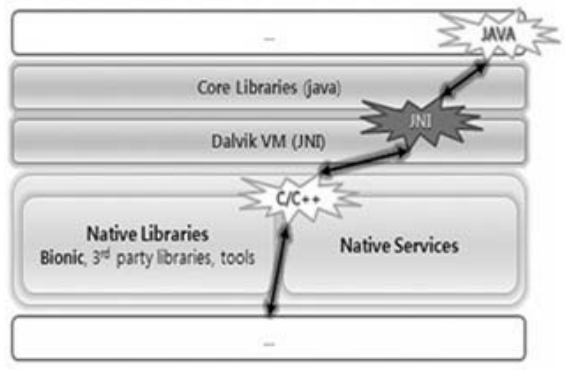

(그림 3) 네이티브 코드 동작 구조

[그림 3]은 안드로이드 플랫폼에서 자바 코드가아 닌 $\mathrm{C} / \mathrm{C}++$ 코드를 구현된 소프트웨어의 동작 구조 〔14]를 도시한 그림이다. 자바 가상 머신 환경에서 자 바 코드는 미디어 처리 성능이 $\mathrm{C} / \mathrm{C}++$ 과 같은 네이 티브 코드에 비해서 낮기 때문에 시그널링 프로토콜 및 음성 미디어 엔진은 네이티브 코드로 구현되며, 사 용자 인터페이스는 자바 코드로 구현되며, 시그널링 프로토콜과 미디어 엔진을 처리 하는 부분은 $\mathrm{JNI}\left(\mathrm{Ja}^{-}\right.$ va Native Interface)롤 연결되어 동작한다.

\section{III. 스마트폰을 위한 HD 보이스 어플리케이션의 구현}

〔그림 4)는 안드로이드 스마트폰에서 구현된 $\mathrm{HD}$ 보이스 어플리케이션의 내부 구조를 도시한 그림이다. 어플레케이션 개발자는 호 관리자(Call Manager), 미디어 관리자(Media Manager), NAT 트래버셜 등의 기능과 인터페이스 역할을 하는 ETRI HD 보이 스 JNI(Java Native Interface)를 이용해서 자바 코드 기반의 ETRI HD 보이스 사용자 인터페이스 어 플리케이션을 개발할 수 있도록 설계 되었다. HD 보 이스 사용자 인터페이스 어플리케이션은 호 처리, 미 디어 처리를 어플리케이션의 목적에 맞게 로직을 수행

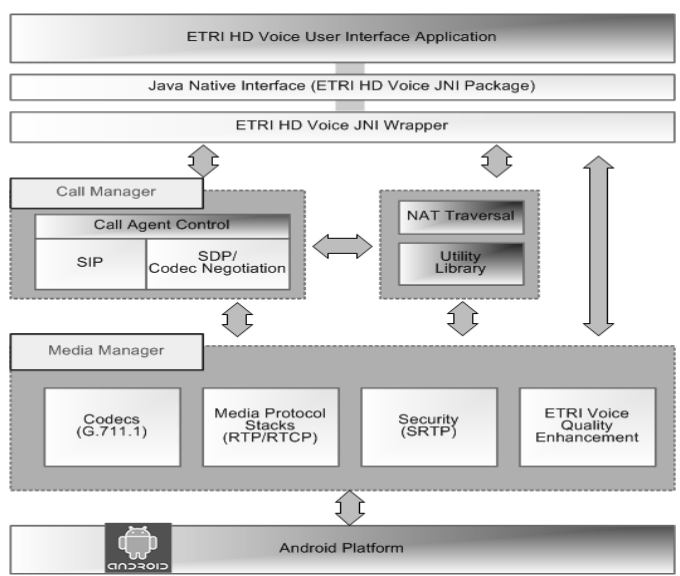

(그림 4) 안드로이드 스마트폰을 위한 HD 보이스 어플리 케이션 구조

하고, 사용자에게 사용자의 입력 이벤트를 받아서 분 석하고 수행하며, 호 관리자나 미디어 관리자에서 발 생하는 이벤트를 사용자에게 알려주는 알려주는 기능 을 수행한다. ETRI JNI Wrapper는 자바 API와 네이티브(Native) API를 연결하는 기능을 수행하며 $\mathrm{C}++$ 코드로 구현되어 있다.

호 관리자는 IETF SIP(Session Initiation Protocol)[5] 와 SDP(Session Descripton Protocol)[6] 표준 문서에 기반한 호 연결 및 미디어 협 상 기능을 수행한다. SIP 스택을 이용해서 상대방 통 화 연결을 처리하는 호 연결 기능을 수행하고, SDP 스택을 이용해서 통화 하기 위한 음성 코덱을 협상하 는 미디어 협상 기능을 수행한다. 미디어 관리자는 호 연결후에 미디어 처리 기능을 수행한다. G.711.1 광 대역 코덱으로 기본으로 포함되어 있으며, 다른 코덱 도 쉽게 이식 될 수 있도록 확장성 있는 구조로 구현 되었다. 미디어 전송 프로토콜로 $\mathrm{IETF}$ 표준 프로토 콜인 RTP(Realtime Transport Protocol)[7]가 구현되어 있으며, 음성 패킷의 보안을 위해서 역시 IETF 표준 프로토콜인 SRTP(Secure Realtime Transport Protocol)를 구현 하였다. ETRI 음성 품질 향상 모듈은 음성 코덱이외에 네트워크 상태, 단 말 상태, 그리고, 화자가 있는 주의환경에 따라서 음 성 품질이 저하 될 수 있는 있기 때문에 저하된 음성 품질을 향상 시키기 위한 기능을 수행한다. ETRI 음 성 품질 향상 모듈은 어커스틱 에코 제거(AECAcoustic Echo Cancellation), 자동 게인 조정 (AGC-Automation Gain Control), 잡음 제거 (Noise Suppressor), TSM(Time Scale Modi- 


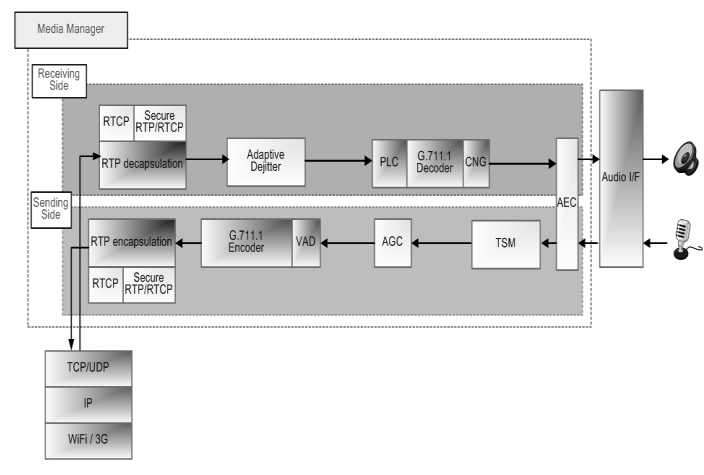

(그림 5) 미디어 관리자의 구조

fication) 기능이 포함되어 있다.

(그림 5)는 미디어 처리 기능을 수행하는 미디어 관리자의 상세 구조를 도시한 그림이다. 미디어 괸라 자의 송신 파트(Sending side)는 6개의 콤포넌트로 구성되어 있다. 스피커와 마이크의 인접한 거리에 의 해서 발생되는 어커스틱 에코를 제거하는 기능을 수행 하는 어커스틱 에코 제거(AEC) 기능은 마이크로 입 력되는 스피커의 신호를 분석해서 제거 한 후에, 상대 방에게 송신해야 하기 때문에, 송신 파트에 서 동작하 게 된다. TSM은 마이크로부터 일정하지 않은 시간으 로 도착한 입력 데이터의 시간차를 보상하기 위한 방 법으로 주요 음성 파라미터 변경 없이, 소리를 빠르 게, 또는 느리게 출력 시키는 기술을 의미한다. 잡음 제거는 음성 품질 저하 없이 신호 대 잡음 비율을 증 가 시켜서 소리에 포함된 잡음을 제거하는 기능을 수 행한다. 자동 게인 제어(AGC)는 자연스럽게 소리의 크기를 조절하는 기능을 수행한다. G.711.1 광대역 코덱 인코더는 PCM(Pulse Code Modulation) 음성 데이터를 G.711.1 비트 스트림으로 인코딩하는 기능을 수행한다. 인코더는 성능 향상을 위해서 ARM Coretex-A 코어에서 어셈블리 코드로 구현되어 있 다.

수신 파트(Receiving side)는 총 5개의 콤포넌트 로 구성되어 있다. 어댑티브 디지터(Adaptive $\mathrm{De}^{-}$ jitter)는 네트워크 상황에 따라서 음성 품질을 저하 시키는 지연과 지터를 해결하기 위한 기능을 수행한 다. G.711.1 광대역 코덱 디코더는 G.711.1 비트 스 트림을 PCM(Pulse Code Modulation) 음성 데 이터로 디코딩하는 기능을 수행한다. PLC(Packet Loss Concealment)는 패킷 손실이 발생 했을 때 에, 손실된 음성 프레임을 보정하기 위한 기능을 수행 한다.

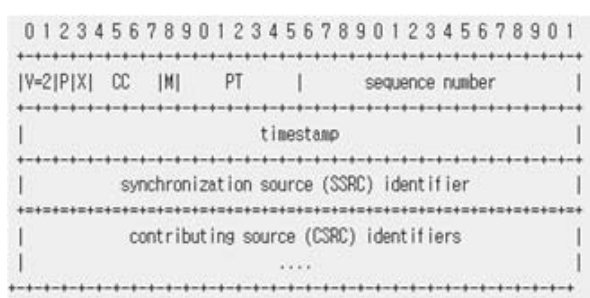

(그림 6) RTP 헤더 구조

다음은 G.711.1 광대역 코덱을 위한 RTP 포맷을 설명한다[9]. [그림 6]은 RTP 헤더 구조를 도시한 그림으로 G.711.1 코덱에 대해서 $\mathrm{M}$ (Marker) 비트 는 정의되어 있지 않다. PT(Payload Type)는 $\mathrm{RTP}$ 페이로드의 데이터 타입을 정의하는데, RTP Profile[10] 표준 문서에 따라서 지정하게 된다. G.711.1 코덱은 동적 페이로드 번호 할당에 해당되 며, 동적 페이로드 번호의 범위는 96에서 127 로 지정 되었다. 본 설계에서는 G.711.1 mu-law 프레임페 이로드는 96으로, G.711.1 A-law 프레임 페이로드 는 87로 지정했다. G.711.1 광대역 코덱의 프레임 크기는 $5 \mathrm{~ms}$ 이고, $16 \mathrm{kHz}$ 이므로 샘플링수는 80 샘 플이 되기 때문에, RTP 타임스탬프는 80 씩 증가하게 된다.

G.711.1 RTP Payload

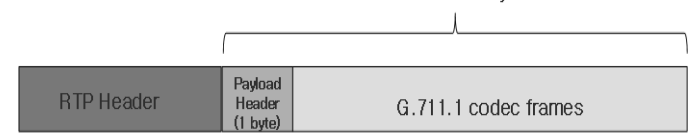

(그림 7) G.711.1 RTP 페이로드 포맷

〔그림 7)은 G.711 RTP 페이로드 포맷의 구조를 됫한 그림으로써, 전체 RTP 페이로드는 1 바이트의 페 이로드 헤더와 나머지 코덱 프레임들로 구성되어 있다.

[그림 8)은 G.711.1 RTP 페이로드 헤더의 구조 를 도시한 그림이다. 1 바이트 중 4 비트는 모드 인덱 스 필드를 나타낸다. 이것은 페이로드 헤더 이후에 RTP 페리로드에 적재되는 G.711.1 코덱 모드를 나

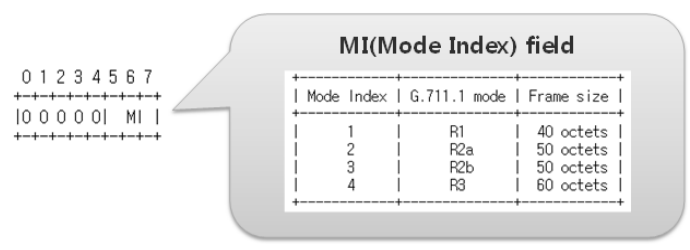

(그림 8) G.711.1 RTP 페이로드 헤더 구조 
타낸다. G.711.1 RTP 페이로드를 수신한 미디어 관 리자의 RTP 처리 모듈은 페이로드 헤더의 모드 인덱 스 필드를 분석해서 모드 인덱스에 정의된 모드는 G.711.1 디코더에게 파라미터로 프레임과 함께 전 달한다. 페이로드 헤더의 나머지 5 비트는 확장을 위 해서 예약되었고, 0 로 셋팅되어야 하며, 이 부분에 대 해서 어떤 동작도 하지 않는다.

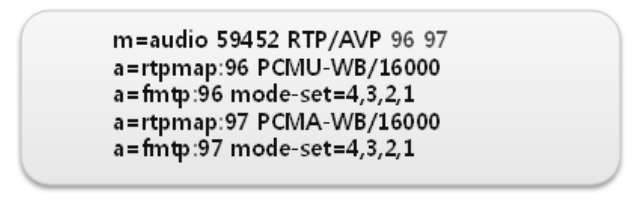

(그림 9) G.711.1 코덱 SDP 포맷

상대방과의 성공적인 $\mathrm{HD}$ 보이스 전화 연결을 위해 서는 코덱 협상 과정이 필요하다. [그림 9]는 G.711.1 코덱 협상을 위한 SDP(Session Description Format) 포맷을 도시한 그림이다. 상세하 게는, mu-law G.711.1 인코딩의 RTP 페이로드 타 입 번호를 위해서 96, A-law G.711.1 인코딩의 $\mathrm{RTP}$ 페이로드 타입 번호를 위해서 97로 정의된다. 또한, mu-law G.711.1 타입의 서브이름은 "PCMU-WB" 이고, A-law G.711.1 타입의 서브이 름은 "PCMA-WB" 로 정의된다. 클럭(clock rate) 은 광대역이므로 " 16000 "으로 정의된다. "mode-set" 파라미터는 현재 $\mathrm{HD}$ 보이스 어플리케이션이 디코딩 가능한 G.711.1 의 코덱 모드를 의미한다. 번호 $4,3,2,1$ 은 각각 R3, R2b, R2a, R1 모드를 의미한 다. 모든 순서에 따라서 우선순위가 정해지는데, (그 림 9]에서 가장 우선순위가 높은 모든 R3(4)모드 이 다. 모드 셋이 SDP 포맷에 나타나지 않으면, 모든 모 드를 디코딩 할 수 있다는 의미를 가진다. 협상 과정 에 의해서, 코덱 모드가 정해지면, 미디어 관리자는 $\mathrm{RTP}$ 페이로드 헤더의 모드 인덱스 필드에 선택된 코 덱 모드를 표시하며, G.711.1 코더에 의해서 인코딩 된 오디오 프레임을 페이로드 뒷부분에 적재한다.

\section{HD 보이스 어플리케이션 성능 시험}

우리는 구현된 $\mathrm{HD}$ 보이스 어플리케이션을 성능 시 험하기 위해서 안드로이드 초기 레퍼런스폰인 HT 넥 서스원을 선택했다. 넥서스원은 퀄컴 QSD8250 프로 세서(snapdragon/1GHz/ARM Cortex-A8)가 탑

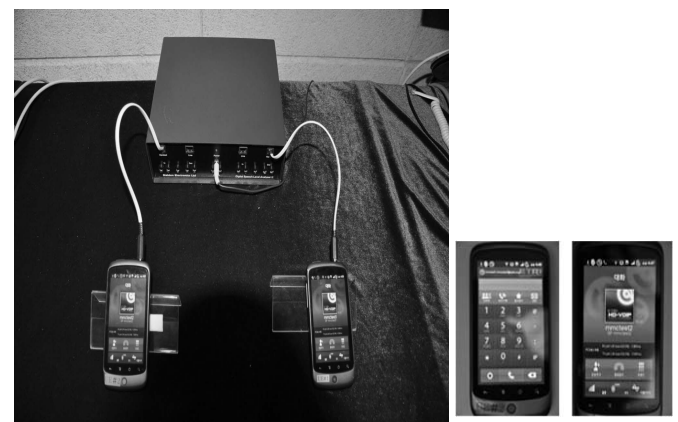

(그림 10〕 HD 보이스 어플리케이션 음성 품질 측정을 위한 시험 환경

재되어 있다. [그림 10]은 우리가 개발한 안드로이드 기반 $\mathrm{HD}$ 보이스 어플리케이션이 스마트폰에 탑재된 상태와 음성 품질을 시험하기 위한 시험 환경을 보여 주는 사진이다. 음성 품질 측정 기준인 MOS(Mena of Opinion)값을 객관적으로 측정하기 위해서 측정 장비 중에 가장 많이 사용하고 검증이 된 Malden Electronics 사의 DSLA II(Digital Speech Level Analyzer II) 장비를 선택해서 $\mathrm{HD}$ 보이스 어플리케이션의 음성 품질을 측정했다. DSLA 음성 품질 측정 장비는 인공적인 음성 신호를 발생해서 시 험 받는 장비를 거쳐서 나오는 결과 신호를 원본 음성 신호와 비교해서 음성 품질을 측정하게 된다. 음성 품 질 측정은 ITU-T P.862〔11〕표준 문서 기준으로 객 관적인 음성 품질을 측정하며, $\mathrm{HD}$ 보이스의 음성 품 질 측정을 위해서 P.862.2〔12〕 표준 문서를 지원하 는 DSLA 측정 장비의 음성 품질 측정 기능을 이용했 다. $\mathrm{HD}$ 보이스 어플리케이션이 두 개의 스마트폰에 탑재되었으며, 스마트폰의 마이크/이어폰 포트는 DSLA 장비에서 나오는 음성 품질 측정을 위한 입력/ 출력 신호 잭이 연결 되었다. 음성 픔질 측정은 두 개 의 스마트폰에서 나오는 이어폰 포트의 신호를 양방향 으로 DLSA에서 잡아서 음성 품질을 측정하게 된다.

〔그림 11)은 HD 보이스 어플리케이션의 음성 품 질을 측정한 결과를 나타내는 그래프이다. 음성 품질 측정은 $\mathrm{HD}$ 보이스 어플리케이션에서 G.711.1, G.722, G.711 코덱을 차례로 선택해서 음성 통화를 연결한 후에, 음성 품질을 측정했다. 또한, 기존에 가 장 많이 사용하는 $\mathrm{HD}$ 보이스급의 S VoIP(Voice over IP) 어플리케이션에 대해서도 같은 조건에서 음 성 품질을 측정했다. 그래프에서 기기존 VoIP 단말에 서 사용하는 G.711 코덱을 적용한 어플리케이션의 음성 품질 보다 G.711.1 코덱을 적용한 어플리케이 


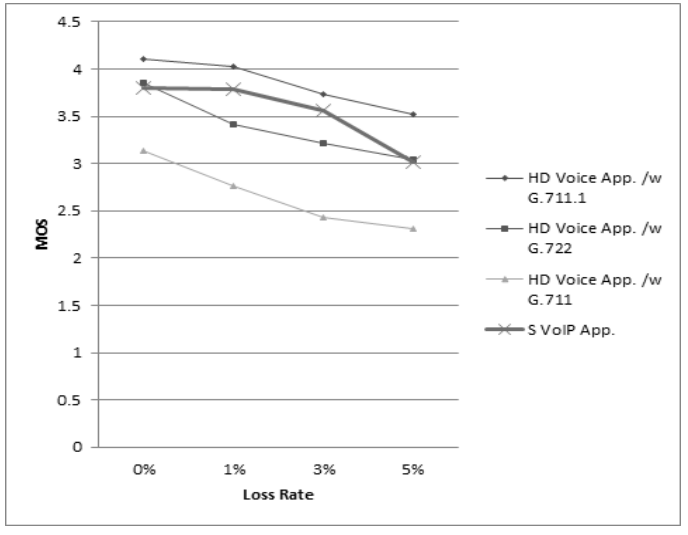

(그림 11) HD 보이스 어플리케이션 음성 품질 측정 결과

션의 음성 품질이 훨씬 좋은 것을 알 수 있다. 또한, 같은 광대역 코덱이라고 하더라도 G.722 보다는 G.711.1 코덱을 적용한 어플리케이션의 음성 품질이 좋은 것을 알 수 있다. $\mathrm{HD}$ 보이스급의 $\mathrm{S} \mathrm{VoIP}$ 어 플리케이션보다는 G.711.1 코덱하에서 우리가 개발 한 $\mathrm{HD}$ 보이스 어플리케이션의 음성 품질이 좋은 것 을 시험 결과를 통해서 알 수 있었다.

\section{V. 결 론}

지금까지 G.711.1 광대역 코덱을 적용한 HD 보 이스 스마트폰 어플리케이션의 구조와 개발된 HD 보 이스 어플리케이션의 음성 품질 시험 결과를 설명하였 다. 개발된 $\mathrm{HD}$ 보이스 스마트폰 어플리케이션은 다 양한 코덱을 이식학 위한 유연성 있는 구조로 되어 있 으며, 코덱 이외에 음성 품질 향상을 위한 기능을 가 지고 있다. 또한 개발된 $\mathrm{HD}$ 보이스 스마트폰 어플리 케이션은 기존 VoIP 단말에서 사용하는 G.711 코덱 을 적용한 어플리케이션의 음성 품질, 같은 광대역 코 덱인 G.722를 적용한 어플리케이션의 음성 품질, 뿐 만 아니라, 기존에 가장 많이 사용하는 HD 보이스급 의 S VoIP 어플리케이션의 음성 품질 보다도 좋은 음성 품질 시험 결과가 도출되었다.

앞으로 연구로는 개발된 호 관리자, 미디어 관리자 들의 $\mathrm{HD}$ 보이스 코어 모듈을 안드로이드 기반 스마 트폰이외에 아이폰 기반으로 $\mathrm{HD}$ 보이스 어플리케이 션을 개발해서 음성 품질을 시험하고자 하며, 기존의 구조에 비디오 기능을 포함한 연구 또한 진행하고자 한다.

\section{참고문헌}

(1] ITU-T, Geneva, Switzerland, ITU-T G.711 - Pulse code modulation (PCM) of voice frequencies, Nov. 1988.

[2] ITU-T, Geneva, Switzerland, ITU-T G.711.1 - Wideband embedded extension for G.711 pulse code modulation, Mar. 2008.

[3] Yuseke Hiwasaki, Hitoshi Phmuto, IEEE Communications Magazine, "Extending G.711 to Higher-Quality Wideband Speech," Jun.2003, pp. 110-116.

(4] Y. Hiwasaki et al., "G.711.1: A Wideband Extension to ITU-T G.711," Proc. EUSIPCO '08, Lausanne, Aug. 2008.

[5] J. Rosenberg, H. Schulzrinne, G. Camarillo, A. Johnston, J. Peterson, R. Sparks, M. Handley, E. Schooler, "SIP(Session Initiation Protocol)," IETF RFC 3261, Jun. 2002.

[6] M. Handley, V. Jacobson, C. Perkins, "SDP(Session Description Protocol)," IETF RFC 4566, Jul. 2006.

〔7] H. Schulzrinne, S. Casner, R. Frederick, V. Jacobson, "RTP: A Transport Protocol for Real-Time Applicationsm," IETF RFC 3550, Jul. 2003.

[8] M. Baugher, D. McGrew, M. Naslund, E. Carrara, K. Norrman, "SRTP: The Secure Real-time Transport Protocol”, IETF RFC 3711, Mar. 2004.

[9] A. Sollaud, "RTP Payload Format for ITU-T Recommendation G.711.1," IETF RFC 5391, Nov. 2008.

〔10] H. Schulzrinne, S. Casner, "RTP Profile for Audio and Video Conferences with Minimal Control," IETF RFC 3551, Jul. 2003.

[11] ITU-T Recommendation P.862, Perceptual evaluation of speech quality (PESQ): An objective method for end-to-end speech quality assessment of narrow-band telephone networks and 
speech codecs, Feb. 2001.

〔12] ITU-T Recommendation P.862.2, Wideband extension to Recommendation P.862 for the assessment of wideband telephone networks and speech codecs, Nov. 2007.

[13] http://developer.android.com/about/ve rsions/index.html.
〔14〕 www.embeddedworld.co.kr, Mar. 2012.

〔15〕 김도영, 성종모, 이미숙, 배현주, 이병선, "음성기 반 오디오 융합코덱 기술동향, 전자통신동향분석 제 24 권 제 5 호, 한국전자통신연구원

[16] Sung, Jongmo, Ko, YunHo, "Transform coding based on source filter model in the MDCT domain," ETRI Journal, Volume 35, Jun. 2013.

\section{〈저 자 소 개〉}
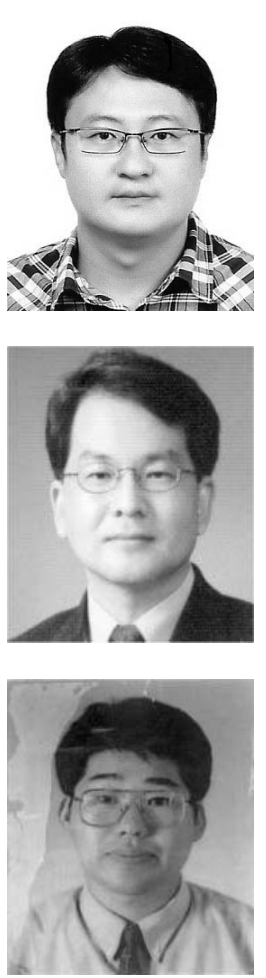

최 승 한 (Seung-han Choi) 정회원 1998년: 충남대학교 컴퓨터공학과 학사 졸업 2000년: 충남대학교 컴퓨터공학과 석사 졸업 2000년 현재: 한국전자통신연구원 선임연구원 재직 2011년 현재: 공주대학교 융합과학과 박사 과정 재학중 〈관심분야〉통신공학, 임베디드 소프트웨어, 멀티미디어 프로토콜, 분산 시스템

김 도 영 (Do-Young $\mathrm{Kim}$ ) 정회원

1985년: 성균관대학교 공학사

1987년: 성균관대학교 공학석사

2007년 : 충남대학교 공학박사

1987년 현재: 한국전자통신연구원 실장/책임연구원

2008년 2009년: 미국 SJSU 전기공학과 객원교수

〈관심분야〉스마트워크, 실감 멀티미디어통신, 실감 멀티미디어 처리, 미래인터넷 서비스

서 창 호 $\left(\mathrm{Seo}^{-} \mathrm{Chang} \mathrm{Ho}\right)$ 종신회원 1990년: 고려대학교 수학과 졸업(학사)

1992년: 고려대학교 수학과(이학석사)

1996년: 고려대학교 수학과(이학박사)

1996년 1996년 : 국방과학연구소 선임연구원

1996년 2000년: 한국전자통신연구원 선임연구원, 팀장

2000년 현재: 공주대학교 응용수학과 교수

관심분야: 암호 알고리즘, $\mathrm{PKI}$, 무선 인터넷 보안 